\title{
EVALUASI KESESUAIAN LAHAN UNTUK BUDIDAYA IKAN DALAM KERAMBA JARING APUNG DI PERAIRAN PESISIR KABUPATEN MAMUJU PROVINSI SULAWESI BARAT
}

\author{
Hasnawi, Akhmad Mustafa, dan Mudian Paena \\ Balai Riset Perikanan Budidaya Air Payau \\ Jl. Makmur Daeng Sitakka No. 129, Maros 90512, Sulawesi Selatan \\ E-mail:vhalowi05@yahoo.co.id
}

(Naskah diterima: 13 Agustus 2010; Disetujui publikasi: 21 Maret 2011)

\begin{abstract}
ABSTRAK
Perairan pesisir Kabupaten Mamuju Provinsi Sulawesi Barat merupakan perairan yang potensial untuk budidaya laut. Namun demikian belum ada data dan informasi kesesuaian lahan untuk budidaya laut termasuk budidaya ikan dalam keramba jaring apung (KJA) di perairan tersebut. Oleh karena itu, dilakukan penelitian yang bertujuan untuk menentukan kesesuaian lahan di perairan pesisir Kabupaten Mamuju untuk budidaya ikan dalam KJA yang diharapkan juga dapat menjadi acuan dalam penentuan tata ruang wilayah pesisir. Metode survai diaplikasi pada wilayah pesisir Kabupaten Mamuju, mulai dari perbatasan Kabupaten Majene di bagian selatan sampai perbatasan Kabupaten Mamuju Utara di utara. Kualitas air perairan yang diukur adalah: pH, salinitas, kecepatan arus, arah arus, kecerahan, kedalaman, nitrat, fosfat, dan besi. Data lainnya diperoleh dari hasil ekstrak citra ALOS AVNIR-2 akuisisi 28 Juli 2009. Analisis spasial dalam Sistem Informasi Geografis digunakan dalam penentuan kesesuaian lahan untuk budidaya ikan dalam KJA. Hasil penelitian menunjukkan bahwa lokasi yang sesuai untuk budidaya ikan dalam KJA di Kabupaten Mamuju tersebar di Pulau Karampuang, Perairan Kalukku, Pulau Bakengkeng, Perairan Papalang, Pulau Kambunong, dan Tanjung Dapurang. Untuk pengembangan kegiatan budidaya ikan dalam KJA yang ramah lingkungan dan berkelanjutan, hanya sekitar $10 \%$ dari potensi perairan pesisir yang secara efektif dimanfaatkan untuk kegiatan budidaya ikan dalam KJA di perairan Kabupaten Mamuju yaitu 698,18 ha yang terdiri atas sangat sesuai seluas 133,18 ha; cukup sesuai 512,41 ha dan kurang sesuai 52,59 ha.
\end{abstract}

KATA KUNCl: kesesuaian lahan, budidaya laut, keramba jaring apung, Kabupaten Mamuju

ABSTRACT: Evaluation of land suitability for fish culture in floating net cages in coastal waters of Mamuju Regency West Sulawesi Province. By: Hasnawi, Akhmad Mustafa, and Mudian Paena

Coastal waters of Mamuju Regency, West Sulawesi Province is a potential area to be developed for mariculture. However, data and information on land suitability for mariculture, including fish culture in floating net cages (FNCS) are not yet available. Hence, research to determine land suitability of Mamuju Regency coastal waters for fish culture in FNCs was conducted, so that it can be used by stakeholders as a reference in management of the coastal area. Survey method was applied in the research taking place on coastal waters of Mamuju Regency, from the border of Majene Regency in southern part to the border of North Mamuju Regency in northern part. Measured water quality of the coastal waters were $\mathrm{pH}$, salinity, current flow, current direction, transparency, water depth, nitrate, phosphate, and iron. The other 
data was extracted from ALOS AVNIR-2 image, acquisition of 28 July 2009. Spatial analysis in Geographical Information System was used to determine the land suitability for fish culture in FNCs. The results showed that the suitable sites for fish culture in FNCs were distributed in Karampuang Island, Kalukku Waters, Bakengkeng Island, Papalang Waters, Kambunong Island, and Dapurang Cape. Of the total area, only 10\% (698.18 ha) was suitable for fish culture in FNCs which was in the coastal waters of Mamuju Regency. The area was classified as highly suitable (133.18 ha), moderately suitable (512.41 ha) and marginally suitable (52.59 ha).

\section{KEYWORDS: land suitability, mariculture, floating net cages, Mamuju Regency}

\section{PENDAHULUAN}

Pantai Kabupaten Mamuju Provinsi Sulawesi Barat berada di Selat Makassar, di mana pada musim Timur terjadi peristiwa fisik laut (upwelling) yang sangat mendukung distribusi hara dan mineral sehingga perairan menjadi subur yang berarti merupakan potensi yang sangat berarti untuk perikanan tangkap dan budidaya di laut. Peluang untuk meningkatkan produksi perikanan budidaya laut di lokasi tersebut cukup besar.

Produktivitas budidaya laut di kawasan perairan pesisirnya sangat dipengaruhi oleh meningkatnya permintaan akan lokasi dan sumberdaya pesisir oleh kegiatan lainnya yang menyebabkan terjadinya kompetisi dalam pemanfaatan ruang dan sumberdaya, terutama aktivitas pelabuhan dan alur pelayaran serta aktivitas lainnya. Semua kegiatan tersebut dapat menyebabkan berkurangnya akses dan kontrol bagi sumberdaya perikanan yang berdampak pada kerusakan habitat ikan.

Untuk meminimalisasi kerusakan habitat ikan dan meningkatkan usaha perikanan budidaya laut yang berlanjut dalam jangka waktu yang panjang, diperlukan adanya tata ruang wilayah pesisir yang sesuai peruntukan masing-masing kegiatan dengan mempertimbangkan karakteristik dan daya dukung lingkungan serta menjaga kelestarian sumberdaya alam dan lingkungan hidup secara bersama-sama. Hal yang perlu diperhatikan dalam keberlanjutan usaha perikanan budidaya laut dalam jangka waktu yang panjang, yaitu kondisi kualitas lingkungan sekitarnya diusahakan tetap baik bagi kontinuitas kegiatan tersebut.

Tahapan awal yang sangat penting untuk menentukan keberhasilan usaha perikanan budidaya yang berkelanjutan di suatu kawasan perairan pesisir adalah pemilihan lokasi.
Apabila salah dalam memilih lokasi untuk pusat pengembangan kegiatan perikanan budidaya laut dapat menyebabkan usaha tersebut tidak berlangsung lama (Beveridge, 1996; Pérez et al., 2003). Dalam hal ini, karakteristik kondisi lingkungan biofisik, kimia, substrat tanah dasar dan air di suatu lokasi sebagai habitat dengan karakter dari biota yang dibudidayakan harus sesuai dengan teknologi budidaya yang diterapkan. Kegiatan usaha perikanan budidaya laut berkelanjutan harus dilandasi dengan perencanaan yang tepat, menyeluruh, dan terpadu dengan rencana sektor lain (Naamin et al., 1991).

Sejalan dengan prinsip penyediaan informasi untuk analisis kewilayahan dalam bentuk peta dari hasil survai yang harus dapat dilaksanakan dengan cepat dan hasilnya segera dapat dimanfaatkan oleh pengguna, maka pemanfaatan teknik penginderaan jauh (inderaja) dan sistem informasi geografis (SIG) merupakan salah satu alternatif yang dapat diandalkan. Pemanfaatan berbagai citra inderaja didukung oleh SIG dapat menghasilkan berbagai macam data dan informasi sumberdaya alam yang relatif cepat dan akurat sesuai dengan kebutuhan para penggunanya (Gunawan \& Herumurti, 2004; Rajitha et al., 2007)). Inderaja yang diintergrasikan dengan SIG dapat memudahkan dalam mendapatkan data dan informasi secara cepat dan akurat tentang kesesuaian lahan pengembangan perikanan budidaya, termasuk budidaya laut. Di sisi lain, menggunakan teknologi SIG ini dapat menyediakan dan menyajikan banyak informasi dalam bentuk gambar yang lebih disukai dan mudah dipahami oleh pengguna. Data inderaja yang diintegrasikan dengan SIG akan membentuk database yang dapat menunjang kebutuhan pengelolaan wilayah pesisir dan laut, khususnya untuk penyusunan tata ruang wilayah pesisir. 
Penelitian ini bertujuan untuk mengetahui kesesuaian lahan untuk budidaya ikan dalam keramba jaring apung (KJA) di perairan pesisir Kabupaten Mamuju Provinsi Sulawesi Barat.

\section{BAHAN DAN METODE}

Kegiatan penelitian pemetaan kesesuaian lahan budidaya laut dilaksanakan di perairan pesisir Kabupaten Mamuju, Provinsi Sulawesi Barat. Penelitian ini menggunakan metode survai yang dirancang berdasarkan SIG. Sebelum pelaksanaan survai, terlebih dahulu dibuat peta panduan survai lapangan yang diturunkan dari interpretasi visual hasil kombinasi natural band citra satelit Advanced
Land Observing Satellite (ALOS) Advanced Visible and Near Infrared Radiometer type 2 (AVNIR-2) (kombinasi band 321) akuisisi 28 Juli 2009 menggunakan software ENVI 4.5 dan image analysis ArcView 3.3, peta Bathymetry (kedalaman) dari Dinas Hidro-Oseanografi TNI-AL, dan peta ketinggian ombak yang diperoleh dari hasil penelitian sebelumnya, serta peta administrasi. Titik-titik pengamatan dan pengambilan contoh air serta pengukuran kedalaman, arah dan kecepatan arus di lokasi penelitian ditentukan berdasarkan peta tersebut. Setiap titik pengamatan dan pengambilan contoh ditentukan posisi atau koordinatnya dengan alat GPS (Global Position-

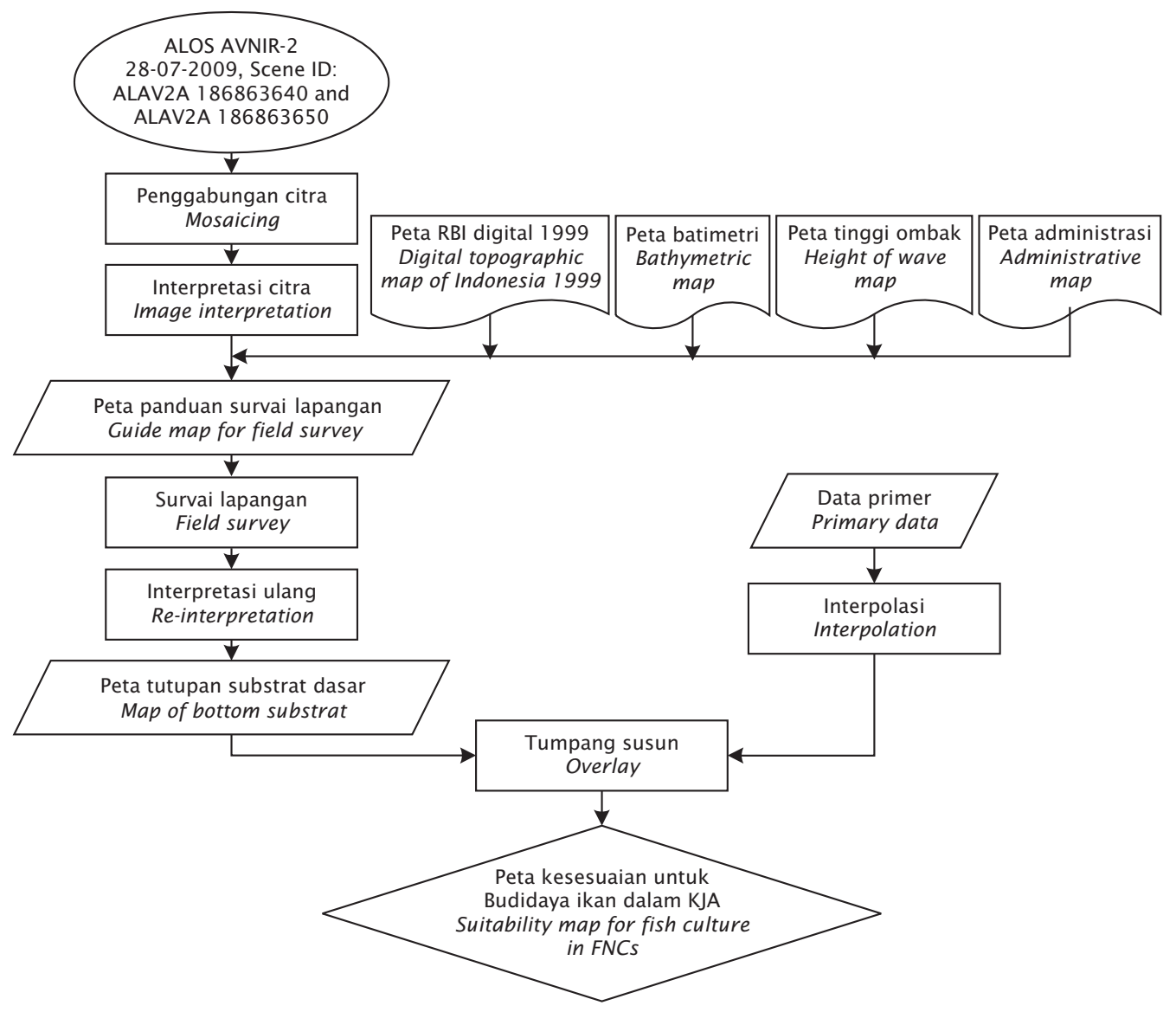

Gambar 1. Skema analisis terintegrasi SIG dan inderaja pada pembuatan peta kesesuaian lahan budidaya ikan dalam keramba jaring apung di perairan pesisir Kabupaten Mamuju Provinsi Sulawesi Barat

Figure 1. Scheme of integrated analysis of geographical information system and remote sensing for land suitability mapping of fish culture in floating net cages in coastal waters of Mamuju Regency West Sulawesi Province 
ing System). Selanjutnya untuk pengamatan biofisik dilakukan di lapangan dan aspek kimiawi air dianalisis di Laboratorium Air Balai Riset Perikanan Budidaya Air Payau di Maros. Metode pengambilan, preservasi dan analisis contoh air mengacu pada APHA (2005). Diagram alir analisis spasial pada pemetaan kesesuaian lokasi lahan budidaya laut dengan menggunakan teknologi SIG disajikan pada Gambar 1.

Data sekunder diperoleh dari peta yang dikumpulkan antara lain peta Rupabumi Indonesia skala 1:50.000 dengan nomor indeks 2014-22/21 (Karossa), 2013-53 (Budongbudong), 2013-51 (Papalang), 2013-23 (Balakalumpang), 2013-14 (Mamuju) dan 201312 (Tapalang), data pasang surut dari Jawatan Hidro-Oseanografi (2009), peta Batimetri (kedalaman) skala 1:200.000 nomor 34 Sulawesi Pantai Barat Doda hingga Tanjung Rangasa dari Dinas Hidro-Oseanografi TNI-AL dan peta administrasi Kabupaten Mamuju. Data pasang surut dianalisis dari data yang diperoleh dari stasiun terdekat yaitu stasiun Mamuju (0240’25,4" LS, $118^{\circ} 53^{\prime}$ '05,2" BT) (Jawatan Hidro-Oseanografi, 2009).
Data primer berupa data fisik dan kimia oseanografis yang diperoleh dari lokasi penelitian meliputi fisik (kedalaman, kecerahan, suhu, kecepatan arus, arah arus) dan kimia air $\left(\mathrm{pH}\right.$, salinitas, $\left.\mathrm{NO}_{3}, \mathrm{PO}_{4}, \mathrm{Fe}\right)$. Kriteria yang digunakan sebagai dasar skala penilaian dan bobot pada kesesuaian lahan untuk budidaya laut (ikan dalam keramba jaring apung) dengan mengacu pada persyaratan yang disarankan oleh Ahmad et al. (1991), Mayunar et al. (1995), Utojo et al. (2005, 2007), dan KLH (2004) seperti disajikan pada Tabel 1.

Untuk masing-masing data fisik dan kimia tersebut dilakukan interpolasi dengan menggunakan metode "kriging", sehingga diperoleh peta-peta tematik untuk tiap peubah (Morain, 1999). Selanjutnya peta-peta tematik tersebut dijadikan input dalam analisis kesesuaian lahan, setelah sebelumnya tiap nilai dikelompokkan berdasarkan kriteria yang telah disusun.

Penilaian terhadap tingkat kesesuaian lahan budidaya laut dilakukan dengan "overlay" (menumpang-susunkan) peta-peta tematik yang telah dibuat dengan metode pembobotan (weighted overlay) pada software ArcGIS 9.3

Tabel 1. Persyaratan tingkat kesesuaian lahan untuk budidaya ikan dalam keramba jaring apung Table 1. Criteria of land suitability for fish culture in floating net cages

\begin{tabular}{|c|c|c|c|c|c|c|c|}
\hline \multirow{2}{*}{$\begin{array}{l}\text { Peubah } \\
\text { Variable }\end{array}$} & \multirow{2}{*}{$\begin{array}{c}\text { Bobot } \\
\text { Weighted } \\
\text { (\%) }\end{array}$} & \multicolumn{2}{|c|}{$\begin{array}{l}\text { Sangat sesuai (S1) } \\
\text { Highly suitable }\end{array}$} & \multicolumn{2}{|c|}{$\begin{array}{l}\text { Cukup sesuai (S2) } \\
\text { Moderately suitable }\end{array}$} & \multicolumn{2}{|c|}{$\begin{array}{l}\text { Kurang sesuai (S3) } \\
\text { Marginally suitable }\end{array}$} \\
\hline & & $\begin{array}{l}\text { Kategori } \\
\text { Category }\end{array}$ & $\begin{array}{l}\text { Skala } \\
\text { Scale }\end{array}$ & $\begin{array}{l}\text { Kategori } \\
\text { Category }\end{array}$ & $\begin{array}{l}\text { Skala } \\
\text { Scale }\end{array}$ & $\begin{array}{l}\text { Kategori } \\
\text { Category }\end{array}$ & $\begin{array}{l}\text { Skala } \\
\text { Scale }\end{array}$ \\
\hline $\begin{array}{l}\text { Ombak }(\mathrm{m}) \\
\text { Wave height }\end{array}$ & 30 & $0.01-0.09$ & 3 & $0.1-1.0$ & 2 & $>1.0$ & 1 \\
\hline $\begin{array}{l}\text { Kedalaman (m) } \\
\text { Depth }\end{array}$ & 20 & $10-15$ & & $16-20$ & & $<10 \&>20$ & \\
\hline $\begin{array}{l}\text { Arus }(\mathrm{cm} / \mathrm{dt}) \\
\text { Current flow }(\mathrm{cm} / \mathrm{sec}\end{array}$ & 15 & $5-10$ & & $11-15$ & & $<5 \&>15$ & \\
\hline $\begin{array}{l}\text { Kecerahan (\%) } \\
\text { Transparency }\end{array}$ & 13 & $80-100$ & & $60-79$ & & $<60$ & \\
\hline $\begin{array}{l}\text { Substrat dasar } \\
\text { Bottom substrate }\end{array}$ & 12 & $\begin{array}{l}\text { Pasir, sedikit } \\
\text { lumpur dan } \\
\text { pecahan } \\
\text { karang } \\
\text { Sand, a little } \\
\text { of mud, coral } \\
\text { fraction }\end{array}$ & & $\begin{array}{l}\text { Pasir, } \\
\text { berlumpur } \\
\text { sedang } \\
\text { Sand, } \\
\text { sufficient of } \\
\text { mud }\end{array}$ & & $\begin{array}{c}\text { Pasir } \\
\text { berlumpur } \\
\text { banyak } \\
\text { Sand, a lot } \\
\text { of mud }\end{array}$ & \\
\hline $\begin{array}{l}\text { Salinitas (ppt) } \\
\text { Salinity }\end{array}$ & 10 & $31-35$ & & $25-30$ & & $<25 \&>35$ & \\
\hline Total & 100 & & & & & & \\
\hline
\end{tabular}


dengan faktor pembobot yang telah disusun (Tabel 1). Pembobotan pada setiap peubah ditentukan berdasarkan pada dominannya peubah tersebut terhadap suatu peruntukan kesesuaian lahan budidaya laut. Kemudian diurutkan peubah-peubah tersebut dimulai dari yang paling berpengaruh terhadap suatu peruntukan. Peubah yang pengaruhnya dominan dan relatif tidak dapat diubah memiliki faktor pembobot yang paling tinggi, peubah yang pengaruhnya sama dengan peubah yang lain memiliki faktor pembobot yang sama, sedangkan peubah yang kurang dominan pengaruhnya memiliki faktor pembobot yang lebih rendah. Nilai total faktor pembobot dari setiap parameter berjumlah $100 \%$.

Menurut Hidayat et al. (1995), pengertian skala penilaian pada kategori kesesuaian tinggi (S1) yaitu, apabila dalam tingkat pengelolaannya sangat didukung oleh peubah biofisik lahan dan karakteristik lingkungannya, sehingga tingkat produksi yang didapatkan tinggi. Kategori kesesuaian sedang (S2), apabila dalam tingkat pengelolaannya mulai terjadi penurunan peubah biofisik lahan, sehingga untuk mendapatkan tingkat produksi yang tinggi disarankan adanya input teknologi, dan kategori kesesuaian rendah (S3), apabila dalam tingkat pengelolaannya disertai dengan penurunan peubah biofisik lahan yang berarti, produksi yang didapatkan rendah sehingga untuk meningkatkan produksi mutlak harus ada input teknologi.

\section{HASIL DAN BAHASAN}

Kedalaman perairan pesisir Kabupaten Mamuju berkisar 2-25 m seperti terlihat pada Tabel 2, sedangkan peta tematik kedalaman pesisir dapat dilihat pada Gambar 3. Kisaran nilai kedalaman tersebut masih cukup baik untuk kegiatan budidaya ikan. Untuk kegiatan budidaya ikan dalam KJA memerlukan kedalaman paling sedikit 4-5 $\mathrm{m}$ dari keramba jaring ke dasar perairan dengan substrat dominan pasir atau pecahan karang (Beveridge, 1996). Menurut Ahmad et al. (1991), kedalaman air laut yang layak untuk kegiatan budidaya ikan dalam KJA lebih dari $5 \mathrm{~m}$. Menurut Mayunar et al. (1995), perairan tempat KJA sebaiknya bertopografi landai, kedalaman 6-8 m, memiliki dasar pasir berlumpur atau lumpur berpasir, airnya jernih dan terhindar dari pelumpuran (siltasi) karena dapat mempengaruhi bobot jaring, kualitas air dan usaha budidaya.

Pasang surut merupakan hal yang penting dalam penentuan lokasi budidaya ikan, karena pasang surut turut mempengaruhi kedalaman perairan. Berdasarkan hasil analisis dari data dari stasiun terdekat yaitu stasiun Mamuju, pengukuran menunjukkan bahwa perubahan pasang surut dalam sehari terjadi dua kali pasang dan sekali surut dengan kisaran yang dapat mencapai 2,1 m. Grafik perubahan pasang surut atau tinggi air di perairan pesisir Kabupaten Mamuju dapat dilihat pada Gambar 2.

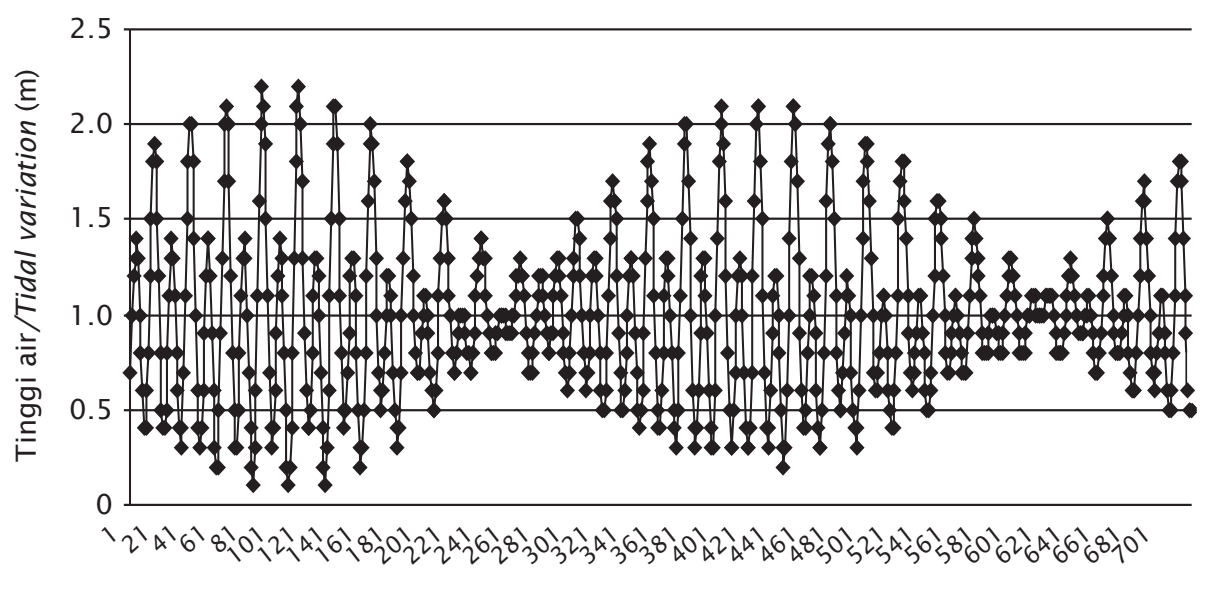

Jam (Hours)

Gambar 2. Tinggi air di perairan pesisir Kabupaten Mamuju Provinsi Sulawesi Barat

Figure 2. Tidal variation in the coastal water of Mamuju Regency, West Sulawesi Province 
Kecerahan perairan pesisir Kabupaten Mamuju berkisar 2-15 m di mana pada kedalaman perairan yang dangkal $(<5 \mathrm{~m})$ kecerahan dapat mencapai $100 \%$ atau sampai ke dasar laut. Pada Gambar 3b terlihat peta tematik kecerahan perairan pesisir Kabupaten Mamuju. Kecerahan perairan untuk kegiatan budidaya ikan dalam KJA haruslah lebih dari $3 \mathrm{~m}$.

Hasil pengukuran kecepatan arus di perairan pesisir Kabupaten Mamuju berkisar 4,05-35,27 cm/dt (Tabel 2, Gambar 4). Kisaran nilai tersebut masih dalam kategori yang baik untuk kegiatan budidaya. Dengan adanya beberapa pulau menyebabkan perairan ini cukup terlindung dan berimplikasi terhadap kondisi kecepatan arus di kawasan perairan pesisir Kabupaten Mamuju, yang umumnya masih dalam kisaran yang baik untuk kegiatan budidaya. Menurut Ahmad et al. (1991), kecepatan arus yang baik untuk kegiatan budidaya ikan dalam KJA berkisar 5-15 cm/dt. Arah arus perlu diketahui untuk menentukan tata letak wadah budidaya sehingga sirkulasi air tetap lancar dan terkendali. Menurut
Mayunar et al. (1995), dalam usaha budidaya ikan dalam keramba jaring apung, desain dan konstruksi keramba harus disesuaikan dengan kecepatan arus dan kondisi dasar perairan (lumpur, pasir, dan karang) serta jenis jangkar yang digunakan.

Salinitas yang didapatkan di perairan pesisir Kabupaten Mamuju berkisar 34-36 ppt (Tabel 2, Gambar 4), merupakan salinitas pada kondisi perairan pesisir. Kisaran salinitas yang sangat sempit ini menunjukkan bahwa tidak ada sumber air tawar yang nyata dapat menurunkan salinitas air di perairan pesisir Kabupaten Mamuju. Umumnya ikan yang hidupnya menetap di laut memiliki toleransi yang tinggi terhadap salinitas. Salinitas dapat mempengaruhi proses osmoregulasi dan merupakan salah satu faktor penentu terhadap pertumbuhan dan sintasannya. Kisaran salinitas yang baik untuk kegiatan budidaya ikan dalam KJA, tergantung pada jenis ikan yang akan dibudidayakan dan lokasi budidaya dengan salinitas yang sesuai untuk pertumbuhan dan sintasannya (Mayunar et al., 1995).

Tabel 2. Kondisi perairan yang diukur langsung di perairan pesisir Kabupaten Mamuju Provinsi Sulawesi Barat

Table 2. Water condition measured in situ in the coastal waters of Mamuju Regency West Sulawesi Province

\begin{tabular}{|c|c|c|c|c|c|c|c|c|}
\hline \multirow[t]{2}{*}{$\begin{array}{l}\text { Stasiun } \\
\text { Station }\end{array}$} & \multicolumn{2}{|c|}{$\begin{array}{l}\text { Koordinat } \\
\text { Coordinate } \\
\quad(\mathrm{m})\end{array}$} & \multirow[t]{2}{*}{$\mathrm{pH}$} & \multirow{2}{*}{$\begin{array}{l}\text { Salinitas } \\
\text { Salinity } \\
\text { (ppt) }\end{array}$} & \multirow{2}{*}{$\begin{array}{c}\text { Arah arus } \\
\text { Direction } \\
\text { of } \\
\text { current } \\
\text { (o) }\end{array}$} & \multirow{2}{*}{$\begin{array}{l}\text { Kecepatan } \\
\text { arus }(\mathrm{cm} / \mathrm{dt}) \\
\text { Flow of } \\
\text { current } \\
(\mathrm{cm} / \mathrm{sec})\end{array}$} & \multirow{2}{*}{$\begin{array}{c}\text { Kecerahan } \\
\text { Transparency } \\
\text { (\%) }\end{array}$} & \multirow{2}{*}{$\begin{array}{c}\text { Kedalaman } \\
\text { Dept } h \\
\text { (m) }\end{array}$} \\
\hline & $x$ & $Y$ & & & & & & \\
\hline 1 & 758764 & 9784474 & 8.26 & 36 & 90 & 5.84 & 43 & 7 \\
\hline 2 & 759527 & 9785714 & 8.31 & 35 & 55 & 20.84 & 75 & 2 \\
\hline 3 & 736916 & 9729834 & 8.31 & 35 & 30 & 5.18 & 57 & 14 \\
\hline 4 & 736419 & 9726944 & 8.26 & 35 & 0 & 4.05 & 40 & 20 \\
\hline 5 & 734943 & 9725736 & 8.23 & 35 & 30 & 12.74 & 87 & 25 \\
\hline 6 & 722877 & 9713157 & 8.25 & 35 & 80 & 7.23 & 100 & 5 \\
\hline 7 & 716479 & 9709308 & 8.49 & 35 & 0 & 10.08 & 100 & 2 \\
\hline 8 & 710858 & 9708557 & 8.32 & 35 & 0 & 6.47 & 25 & 16 \\
\hline 9 & 709428 & 9710600 & 8.42 & 35 & 310 & 8.63 & 100 & 6 \\
\hline 10 & 708859 & 9708681 & 8.28 & 35 & 150 & 12.58 & 100 & 2 \\
\hline 11 & 700592 & 9707335 & 8.43 & 35 & 220 & 6.70 & 100 & 3 \\
\hline 12 & 704585 & 9708280 & 8.33 & 35 & 120 & 25.63 & 100 & 3 \\
\hline 13 & 706716 & 9705444 & 8.39 & 35 & 330 & 9.59 & 47 & 17 \\
\hline 14 & 709902 & 9706360 & 8.3 & 35 & 90 & 35.27 & 79 & 19 \\
\hline 15 & 713407 & 9706447 & 8.29 & 34 & 255 & 20.28 & 100 & 2 \\
\hline 16 & 711841 & 9705508 & 8.27 & 34 & 345 & 7.70 & 100 & 15 \\
\hline \multicolumn{3}{|c|}{ Optimum } & $7.0-8.5$ & $30-36$ & - & $5-10$ & $80-100$ & $10-15$ \\
\hline
\end{tabular}



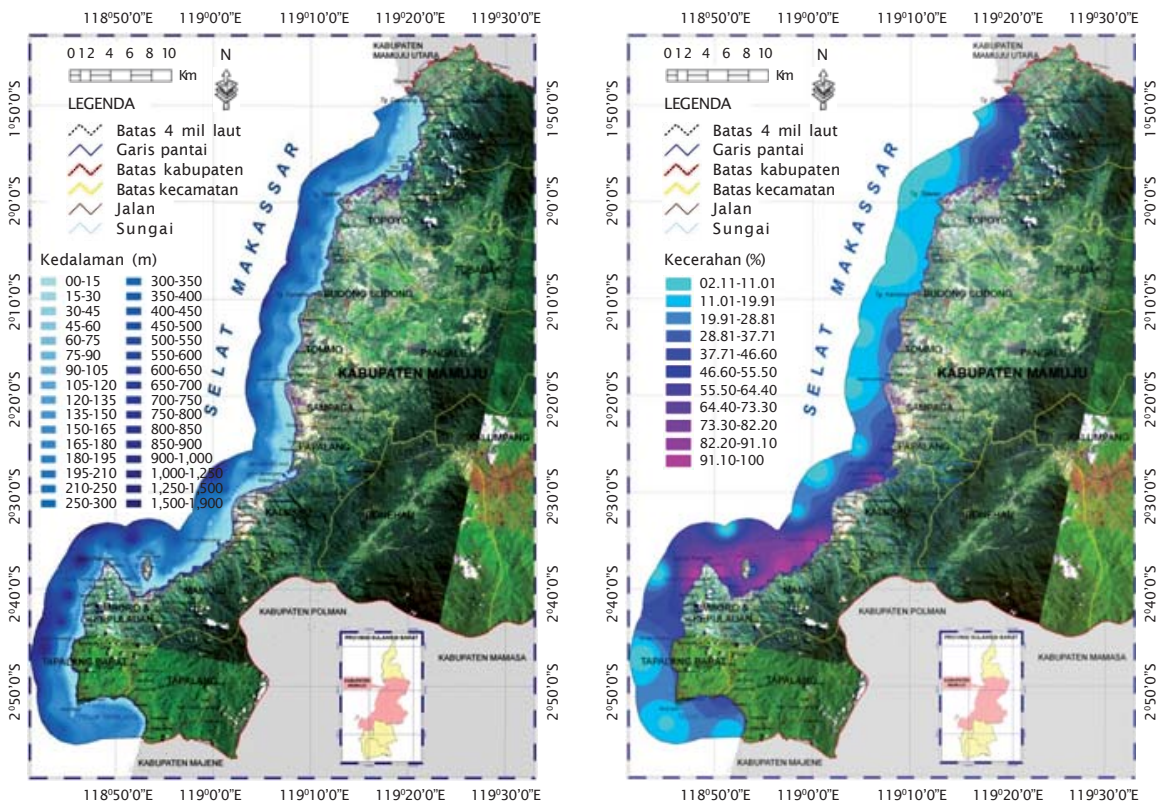

Gambar 3. Peta tematik kedalaman (a) dan kecerahan (b) perairan pesisir Kabupaten Mamuju Provinsi Sulawesi Barat

Figure 3. Thematic map of water depth (a) and transparency (b) in the coastal waters of Mamuju Regency West Sulawesi Province
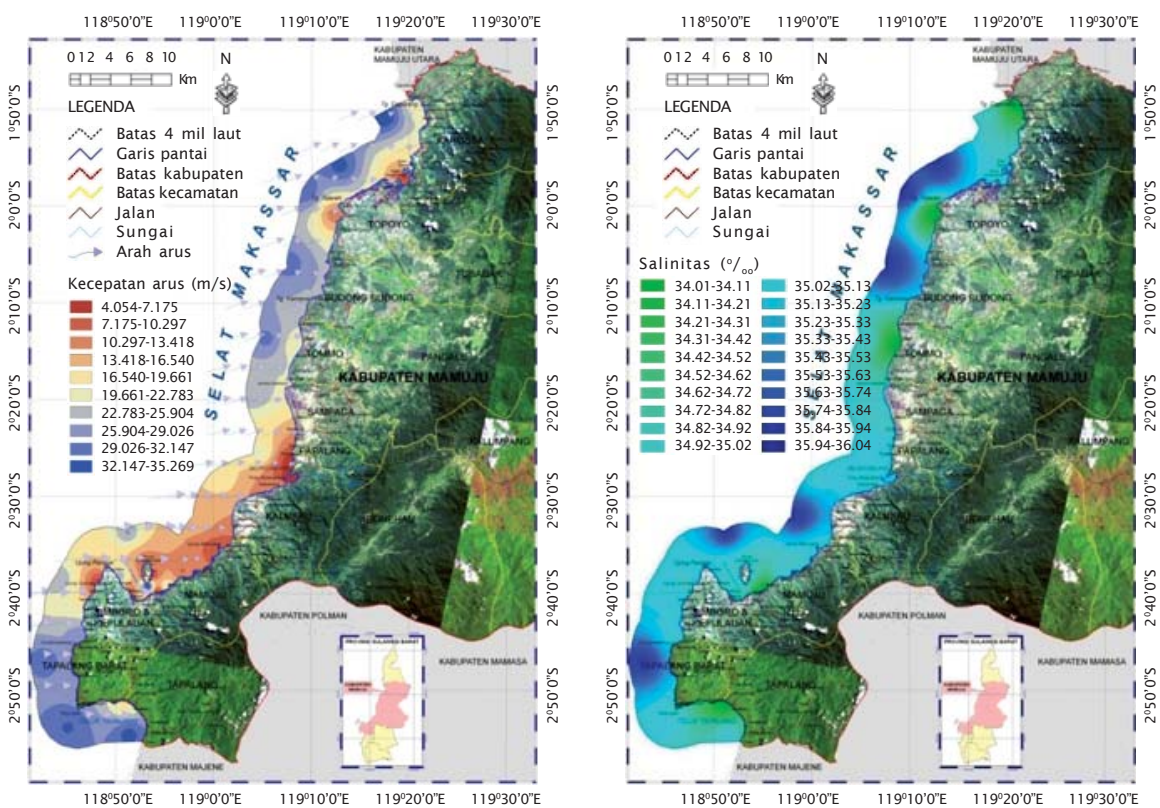

Gambar 4. Peta tematik kecepatan arus (a) dan salinitas (b) perairan pesisir Kabupaten Mamuju Provinsi Sulawesi Barat

Figure 4. Thematic map of water current (a) and salinity (b) in the coastal waters of Mamuju Regency West Sulawesi Province 
Kisaran nilai $\mathrm{pH}$ yang didapatkan di lokasi survai antara 8,23-8,49 merupakan derajat keasaman yang relatif stabil di perairan pesisir. Pada kondisi laut umumnya memiliki nilai $\mathrm{pH}$ berkisar 7,5-8,5. Untuk itu kisaran nilai tersebut masih dalam kategori baik dan layak untuk kegiatan budidaya ikan dalam KJA di laut. Menurut KLH (2004), nilai pH dalam baku mutu air laut untuk kegiatan budidaya perikanan yang diinginkan berkisar 7,0-8,5.

Hasil analisis kualitas air di laboratorium dan pengukuran di lokasi survai dapat dilihat pada Tabel 3. Kandungan amonia $\left(\mathrm{NH}_{3}\right)$ di perairan umumnya bersifat toksik pada ikan dan organisme lainnya, sedangkan nitrat $\left(\mathrm{NO}_{3}\right)$ hanya bersifat toksik pada kandungan tinggi. Kandungan nitrat $\left(\mathrm{NO}_{3}\right)$ yang didapatkan di lokasi survai berkisar 0,013-0,453 mg/L. Kisaran nilai tersebut tergolong agak tinggi untuk kegiatan budidaya laut. Menurut KLH (2004), kandungan nitrat perairan pesisir yang diinginkan untuk kegiatan budidaya perikanan yaitu $0,008 \mathrm{mg} / \mathrm{L}$. Kandungan fosfat $\left(\mathrm{PO}_{4}\right) \mathrm{di}$ perairan merupakan indikator kesuburan, apabila kandungan tersebut terlalu tinggi akan terjadi eutrofikasi yang menyebabkan penurunan oksigen terlarut secara drastis terutama menjelang pagi hari dan berakibat pada kematian ikan yang dibudidayakan. Kandungan fosfat yang didapatkan di lokasi survai berkisar 0,016-0,056 mg/L. Kandungan fosfat tersebut memiliki kisaran nilai yang agak rendah, tetapi masih dalam kategori baik untuk kegiatan budidaya perikanan. Kandungan fosfat umumnya disebabkan adanya akumulasi partikel organik dari erosi tanah, buangan hewan dan pembusukan organisme. Untuk keperluan budidaya ikan, kandungan fosfat perairan yang baik dan aman berkisar $0,2-0,5$ $\mathrm{mg} / \mathrm{L}$ (Mayunar et al., 1995). Sedangkan KLH (2004) kandungan fosfat yang diinginkan dalam kegiatan budidaya perikanan yaitu $0,015 \mathrm{mg} / \mathrm{L}$.

Tabel 3. Kualitas air di perairan pesisir Kabupaten Mamuju Provinsi Sulawesi Barat yang dianalisis di laboratorium

Table 3. Water quality of the coastal waters measured in laboratory in Mamuju Regency West Sulawesi Province

\begin{tabular}{|c|c|c|c|c|c|}
\hline \multirow{2}{*}{$\begin{array}{l}\text { Stasiun } \\
\text { Station }\end{array}$} & \multicolumn{2}{|c|}{$\begin{array}{c}\text { Koordinat } \\
\text { Coordinate }(\mathrm{m})\end{array}$} & \multirow{2}{*}{$\begin{array}{l}\text { Nitrat } \\
\text { Nitrate } \\
(\mathrm{mg} / \mathrm{L})\end{array}$} & \multirow{2}{*}{$\begin{array}{l}\text { Besi } \\
\text { Iron } \\
(\mathrm{mg} / \mathrm{L})\end{array}$} & \multirow{2}{*}{$\begin{array}{c}\text { Fosfat } \\
\text { Phosphate } \\
\text { (mg/L) }\end{array}$} \\
\hline & $\mathbf{X}$ & $\mathrm{Y}$ & & & \\
\hline 1 & 758764 & 9784474 & 0.453 & 0.034 & 0.054 \\
\hline 2 & 759527 & 9785714 & 0.275 & 0.025 & 0.034 \\
\hline 3 & 736916 & 9729834 & 0.158 & 0.028 & 0.036 \\
\hline 4 & 736419 & 9726944 & 0.042 & 0.035 & 0.056 \\
\hline 5 & 734943 & 9725736 & 0.035 & 0.022 & 0.021 \\
\hline 6 & 722877 & 9713157 & 0.051 & 0.021 & 0.038 \\
\hline 7 & 716479 & 9709308 & 0.042 & 0.029 & 0.034 \\
\hline 8 & 710858 & 9708557 & 0.055 & 0.027 & 0.034 \\
\hline 9 & 709428 & 9710600 & 0.036 & 0.028 & 0.031 \\
\hline 10 & 708859 & 9708681 & 0.031 & 0.039 & 0.029 \\
\hline 11 & 700592 & 9707335 & 0.026 & 0.022 & 0.040 \\
\hline 12 & 704585 & 9708280 & 0.022 & 0.030 & 0.024 \\
\hline 13 & 706716 & 9705444 & 0.013 & 0.044 & 0.024 \\
\hline 14 & 709902 & 9706360 & 0.015 & 0.045 & 0.030 \\
\hline 15 & 713407 & 9706447 & 0.022 & 0.039 & 0.026 \\
\hline 16 & 711841 & 9705508 & 0.026 & 0.020 & 0.016 \\
\hline \multicolumn{3}{|c|}{ Optimum } & 0.008 & $<0.1$ & $0.2-0.5$ \\
\hline
\end{tabular}




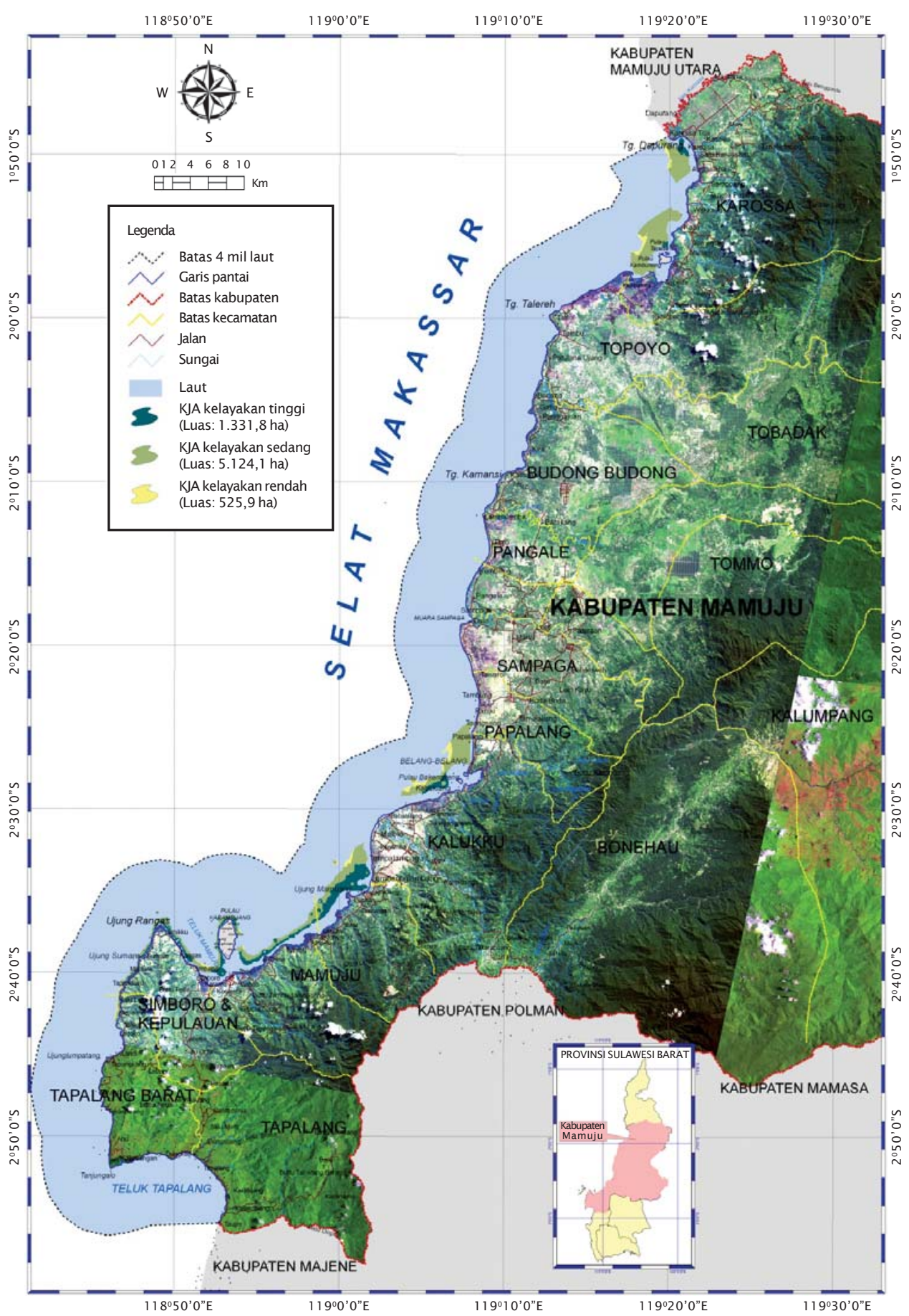

Gambar 5. Peta kesesuaian lahan budidaya ikan dalam keramba jaring apung di kawasan perairan pesisir Kabupaten Mamuju Provinsi Sulawesi Barat

Figure 5. Map of land suitability for fish culture in floating net cages in coastal waters of Mamuju Regency West Sulawesi Province 
Dari hasil analisis kesesuaian lahan untuk budidaya ikan dalam KJA dengan berdasar kriteria seperti pada Tabel 1, maka tingkat kesesuaian lahan untuk kegiatan budidaya laut dapat diidentifikasi dan disajikan dalam bentuk peta (Gambar 5). Lokasi yang sesuai untuk budidaya ikan dalam KJA tersebar di Tanjung Dapurang, Pulau Kambunong, Perairan Papalang, Pulau Bekengkeng, Perairan Kalukku, dan Pulau Karampuang di mana tingkat kesesuaian lahan tinggi, sedang dan rendah dijumpai di setiap lokasi tersebut. Tingkat kesesuaian lahan rendah umumnya dijumpai di bagian luar, tingkat kesesuaian rendah pada bagian tengah dan tingkat kesesuaian tinggi pada bagian dalam dari setiap lokasi tersebut. Dari Gambar 5 terlihat bahwa luas lahan yang sesuai untuk budidaya ikan dalam KJA di Kabupaten Mamuju adalah 6.981,8 ha yang terdiri atas kesesuaian tinggi seluas 1.331,8 ha $(19,1 \%)$, kesesuaian sedang seluas $5.124,1$ ha $(73,4 \%)$ dan kesesuaian rendah seluas 525,9 ha $(7,5 \%)$.

Untuk pengembangan kegiatan budidaya ikan dalam KJA yang ramah lingkungan dan berkelanjutan, maka potensi yang ada sekiranya tidak dimanfaatkan seluruhnya, melainkan harus disediakan untuk kawasan penyangga dan aktivitas perikanan yang lain. Dari luasan tersebut, hanya sekitar $10 \%$ dari potensi perairan pesisir yang secara efektif dimanfaatkan untuk kegiatan budidaya ikan dalam KJA yaitu 698,18 ha yang terdiri atas tingkat kesesuaian tinggi seluas 133,18 ha; sedang 512,41 ha; dan rendah 52,59 ha. Dengan pertimbangan bahwa setiap hektar lokasi kegiatan budidaya dapat dimanfaatkan secara efektif untuk 100 unit KJA yang setiap unitnya terdiri atas 4 keramba dengan ukuran per keramba 1,5 $\mathrm{m} \times 1,5 \mathrm{~m} \times 2,5 \mathrm{~m}$. Menurut Imanto (2000), setiap hektar lokasi budidaya dapat dimanfaatkan secara efektif untuk 40 unit KJA yang setiap unitnya terdiri atas 4 keramba dengan ukuran 2,5 m x 2,5 m x 3,5 m dan padat tebar ikan optimumnya mencapai 20 ekor $/ \mathrm{m}^{3}$ dengan ukuran benih 7-10 g (3-4 $\mathrm{cm})$.

\section{KESIMPULAN DAN SARAN}

Lokasi yang sesuai untuk budidaya ikan dalam KJA di Kabupaten Mamuju Provinsi Sulawesi Barat tersebar di Tanjung Dapurang, Pulau Kambunong, Perairan Papalang, Pulau Bekengkeng, Perairan Kalukku, dan Pulau Karampuang. Untuk pengembangan kegiatan budidaya ikan dalam KJA yang ramah lingkungan dan berkelanjutan, hanya sekitar $10 \%$ dari potensi perairan pesisir yang secara efektif dimanfaatkan untuk kegiatan budidaya ikan dalam KJA yaitu 698,18 ha yang terdiri atas tingkat kesesuaian tinggi seluas 133,18 ha; sedang 512,41 ha; dan rendah 52,59 ha.

\section{UCAPAN TERIMA KASIH}

Terima kasih diucapkan kepada Darsono atas bantuannya dalam pengambilan contoh air di lapangan dan Sutrisyani, Andi Sahrijanna, dan Sitti Rohani atas bantuannya dalam analisis air di laboratorium.

\section{DAFTAR ACUAN}

Ahmad, T., Imanto, P.T., Muchari, Basyarie, A., Sunyoto, P., Slamet, B., Mayunar, Purba, R., Diana, S., Redjeki, S., Pranowo, S.A., \& Murtiningsih, S. 1991. Operasional Pembesaran Ikan Kerapu dalam Keramba Jaring Apung. Balai Penelitian Perikanan Budidaya Pantai, Pusat Penelitian dan Pengembangan Perikanan, Departemen Pertanian, Jakarta, $59 \mathrm{hlm}$.

APHA (American Public Health Association). 2005. Standard Methods for Examinition of Water and Wastewater. APHA-AWWA-WEF, Washington DC, 1,185 pp.

Beveridge, M.C.M. 1996. Cage Aqua-culture. $2^{\text {nd }}$ edition. Fishing News Books LTD. Farnham, Surrey, England, 352 pp.

Gunawan, T. \& Herumurti, S. 2004. Pemanfaatan penginderaan jauh dan sistem informasi geografis untuk mendukung inventarisasi dan pengelolaan sumberdaya wilayah pesisir di Kabupaten Gresik dengan pendekatan survai cepat terintegrasi. Dalam: Danoedoro, P. (ed.), Sains Informasi Geografis dari Perolehan dan Analisis Citra hingga Pemetaan dan Pemodelan Spasial. Fakultas Geografi Universitas Gadjah Mada, Yogyakarta, hlm. 249-262.

Hidayat, A., Soekardi, M., \& Ponidi. 1995. Kajian kesesuaian lahan untuk mendukung pembangunan perikanan pantai dan pertanian di daratan Kasipute-Lainea, Sulawesi Tenggara. Dalam: Laporan Akhir Hasil Penelitian Potensi dan Hasil Kesesuaian Lahan untuk Pengembangan Perikanan Pantai (Tingkat Tinjau Mendalam) Daerah Kasipute-Lainea, Sulawesi Tenggara. Pusat Penelitian Tanah dan Agroklimat Bekerjasama dengan Proyek Pembinaan 
Kelembagaan Penelitian Pertanian Nasional, Jakarta, hlm. 96-162.

Imanto, P.T. 2000. Budidaya Ikan Laut. Workshop Pengelolaan Sumberdaya Perikanan Berbasis Komunitas 20-22 November 2000, Lombok Timur, $19 \mathrm{hlm}$.

Jawatan Hidro-Oseanografi. 2009. Daftar Pasang Surut Kepulauan Indonesia tahun 2009. Jawatan Hidro-Oseanografi TNI-AL, Jakarta, $679 \mathrm{hlm}$.

KLH. 2004. Keputusan Menteri Negara Kependudukan dan Lingkungan Hidup No. 51 Tahun 2004, Tanggal 8 April 2004 tentang Baku Mutu Air Laut untuk Biota Laut. Kementerian Lingkungan Hidup, Jakarta, 11 hlm.

Mayunar, Purba, R., \& Imanto, P.T. 1995. Pemilihan lokasi untuk usaha budidaya ikan laut. Dalam: Sudradjat, A., W. Ismail, B. Priono, Murniyati dan E. Pratiwi (Eds.). Prosiding Temu Usaha Pemasyarakatan Teknologi Keramba Jaring Apung bagi Budidaya Laut, Jakarta, 12-13 April 1995, hlm. 179-189.

Morain, S. 1999. GIS Solution in Natural Resource Management: Balancing the Technical Political Equation. On Word Press. USA, $361 \mathrm{pp}$.

Naamin, N., Cholik, F., Ilyas, S., Dwiponggo, Ahmad, T., Widodo, J., \& Ismail, W. 1991.
Petunjuk Teknis Pengelolaan Perairan Laut dan Pantai bagi Pembangunan Perikanan. Pusat Penelitian dan Pengembangan Perikanan, Badan Penelitian dan Pengembangan Pertanian, Departemen Pertanian, Jakarta, $88 \mathrm{hlm}$.

Pérez, O.M., Ross, L.G., Telfer, T.C., \& del Campo Barquin, L.M. 2003. Water quality requirements for marine fish cage site selection in Tenerife (Canary Islands): predictive modelling and analysis using GIS. Aquaculture, 224: 51-68.

Rajitha, K., Mukherjee, C.K., \& Chandran, R.V. 2007. Applications of remote sensing and GIS for sustainable management of shrimp culture in India. Aquacultural Engineering, 36: 1-17.

Utojo, Mansyur, A., Tarunamulia, Pantjara, B., \& Hasnawi. 2005. Identifikasi kelayakan lokasi lahan budidaya laut di perairan Teluk Kupang, Nusa Tenggara Timur. J. Pen. Perik. Indonesia, 11(5): 9-29.

Utojo, Mansyur, A., Mustafa, A., Hasnawi, \& Tangko, A.M. 2007. Pemilihan lokasi budidaya ikan, rumput laut, dan tiram mutiara yang ramah lingkungan di Kepulauan Togean, Sulawesi Tengah. J. Ris. Akuakultur, 2(3): 303-318. 